\title{
What Were the Use Patterns Observed at the Highly Utilized Direct Current Fast Charge Sites?
}

Idaho National Laboratory

June 2015

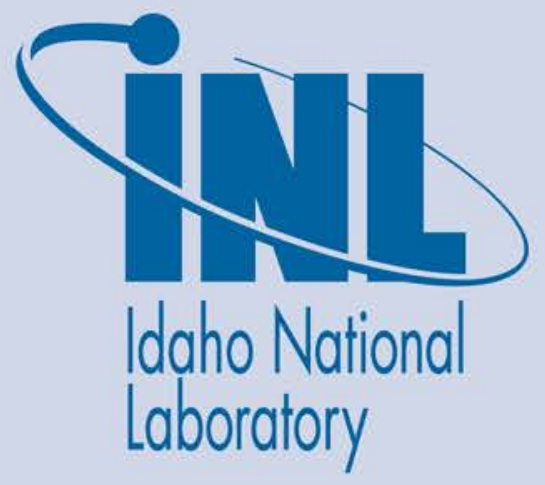

The INL is a U.S. Department of Energy National Laboratory operated by Battelle Energy Alliance 
INL/EXT-16-35816

\title{
What Were the Use Patterns Observed at the Highly Utilized Direct Current Fast Charge Sites?
}

\author{
Idaho National Laboratory
}

June 2015

\section{Idaho National Laboratory \\ Idaho Falls, Idaho 83415}

http://www.inl.gov

\author{
Prepared for the \\ U.S. Department of Energy \\ Assistant Secretary for _, OR Office of \\ Under DOE Idaho Operations Office \\ Contract DE-AC07-05ID14517
}




\section{$=$ V Project}

\section{What Were the Use Patterns Observed at the Highly Utilized Direct Current Fast Charge Sites?}

June 2015

\section{Key Conclusions}

- Leaf drivers in The EV Project were an average of 17.1 miles from their home when charging at the most frequently utilized direct current fast chargers (DCFC).

- The average EV Project Leaf battery state-of-charge (SOC) was $35.3 \%$ when DCFC was initiated at these stations.

- Charging by Leaf drivers at the most frequently utilized DCFCs occurred uniformly throughout the entire week.

- DCFC stations were used most frequently between 4 and 7 p.m.

\section{Introduction}

The EV Project deployed over 100 DCFCs that utilized the CHAdeMO charging standard [1]. The Nissan Leaf vehicle option for fast charge capability was included on all Leaf vehicles that participated in The EV Project.

This paper will examine use of the most highly utilized DCFC units in The EV Project and analyze the conditions under which the user elected to charge at those DCFCs. The DCFC stations examined for this paper had an average of 33 charge events per week. Twenty DCFC stations that were used an average 20.8 to 66 times per week

The user-based conditions evaluated for this paper include the battery's indicated SOC at charge start, distance away from home when charging took place, day of the week the plug-in electric vehicle (PEV) driver elected to fast charge, and time of day when charging took place.

\section{Data Analyzed}

Data analyzed come from both the Nissan Leaf vehicle data provided to the Idaho National Laboratory's (INL's) Advanced Vehicle Testing Activity and from Blink DCFCs.
At each Leaf's key-on and key-off events, the time and location of the vehicle and the Leaf's vehicle identification, odometer, and indicated battery SOC were recorded. A change in SOC between key off and key on indicated that a charge had taken place. Data provided for the same time and location by the Blink DCFC include time and location, length of time connected, length of time charging, and amount of energy transferred during the charging event.

\section{Analyses Performed}

Analyzing these data, this paper examines the conditions when and where DCFC charging took place and at what indicated battery SOC the Leaf driver elected to fast charge. The most used DCFC stations are examined in an attempt to identify conditions under which DCFC use may be maximized in the future.

One of the key factors that changed during conduct of The EV Project was introduction of fees for charging. The Blink DCFC stations introduced fees during the summer of 2013. Fee introduction did not take place simultaneously across the market or across the most frequently used DCFC stations analyzed for this paper. Therefore, when appropriate, data are presented across the entire term of The EV Project and in subsets where most or all DCFC stations had implemented fees for use of the DCFC stations. Most DCFC stations implemented fees during the third quarter of 2013. All markets had implemented fees by the fourth quarter.

The following discussion examines when, where, and at what SOC the Leaf driver initiated a fast charge.

\section{Discussion of Results}

\section{When were the Frequently Used Direct Current Fast Chargers Used?}

Data collected from the fast charge events in The EV Project provided the time and day the fast charging took place. Examination of the day of the week the DCFC stations were used reveled that they were used uniformly throughout the week. Figure 1 shows the quantity of DCFC charge events per day. Sunday is the only day that had use well below average (i.e., $80 \%$ of the average number), while all of the days from Tuesday through Saturday were within $10 \%$ of the average. As can be seen in Figure 2, this uniformity also held true over the last 6 months of 2013. Again, Sunday and Monday were the days with the least amount of charging activity; however, as seen in the overall project, use on all of the other days is fairly uniform. 
Further investigation regarding the hour of the day these DCFCs were used shows that the end of the workday or shortly following the end of the workday was the most popular. Figure 3 shows that throughout The EV Project time period and during the last 6 months, the time between 4 and 7 p.m. was when most fast charging occurred. There also was an increase in use around the lunch hours (i.e., between 11 a.m. and 1 p.m.).

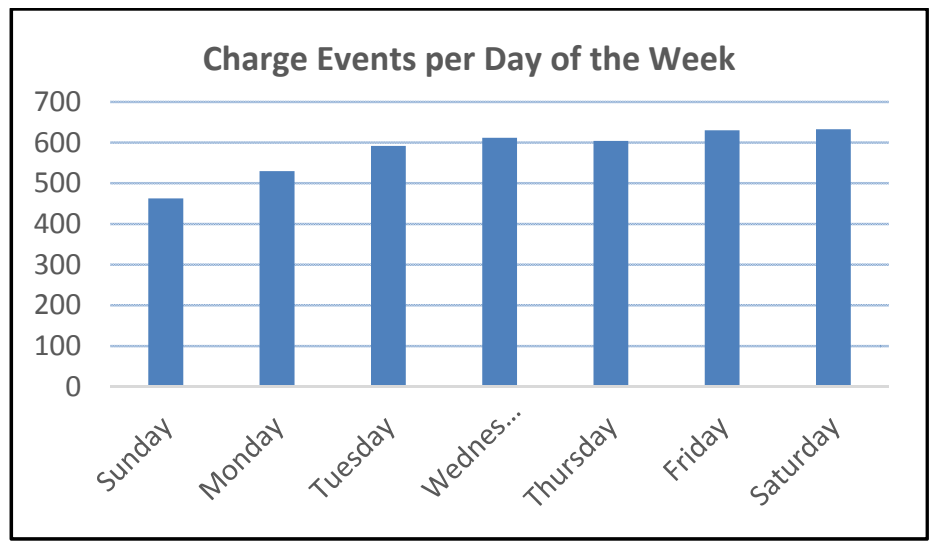

Figure 1. Day of the week when popular DCFCs were used (over the full term of The EV Project).

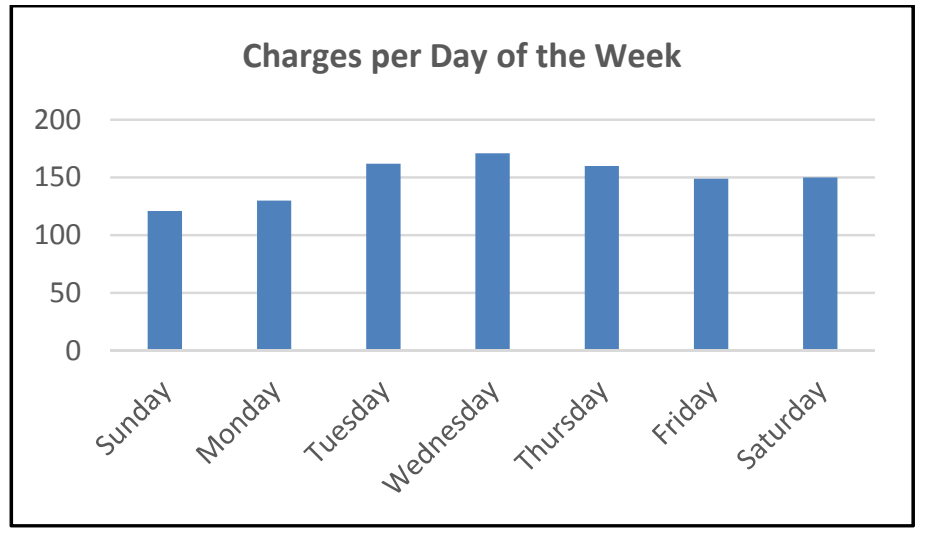

Figure 2. Day of the week when popular DCFCs were used (last six months of 2013).

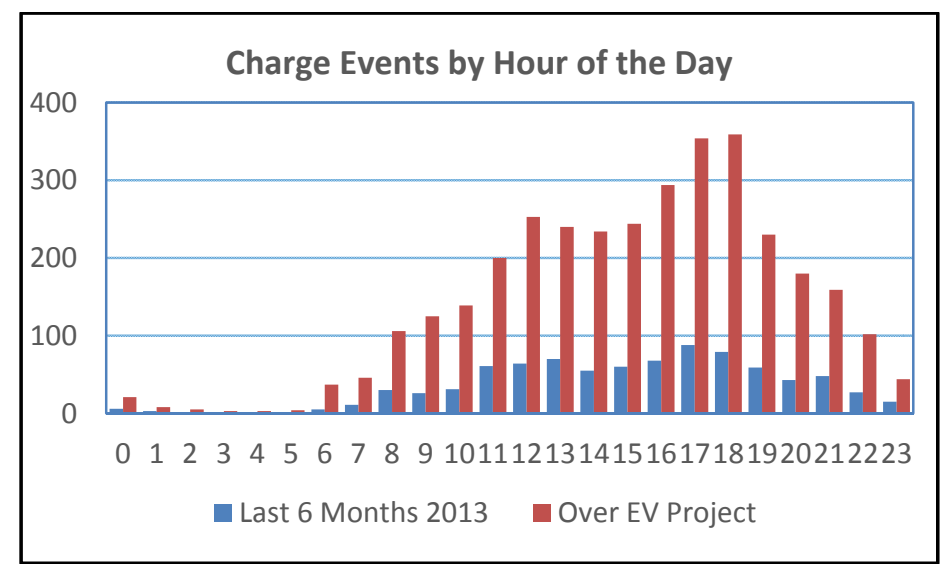

Figure 3. Hour of the day when popular DCFCs were used.
Figures 4 and 5 display not only the last 6 months, when most DCFC stations had implemented fees, but also the fourth quarter when all studied DCFCs had implemented fees. Figure 5 removes the overall EV Project data in order to more closely examine the shape of the DCFC use curves for the last six months of 2013 and the last three months of 2013. This graph shows that although there were significantly fewer charge events per hour of the day, the hours of day with the most charging occurs is still clearly from 4 to 7 p.m.

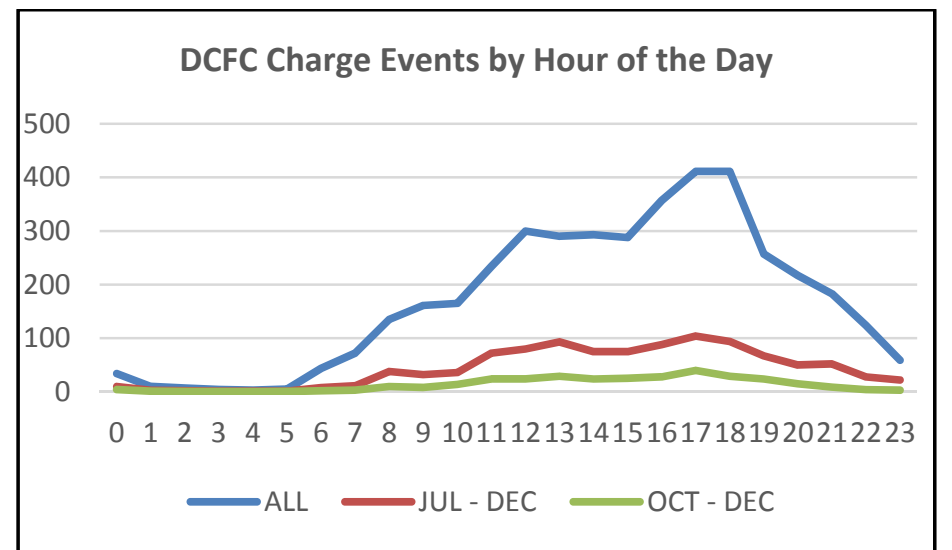

Figure 4. Hour of the day when popular DCFCs were used during all of The EV Project, the last 6 months, and the last 3 months of 2013.

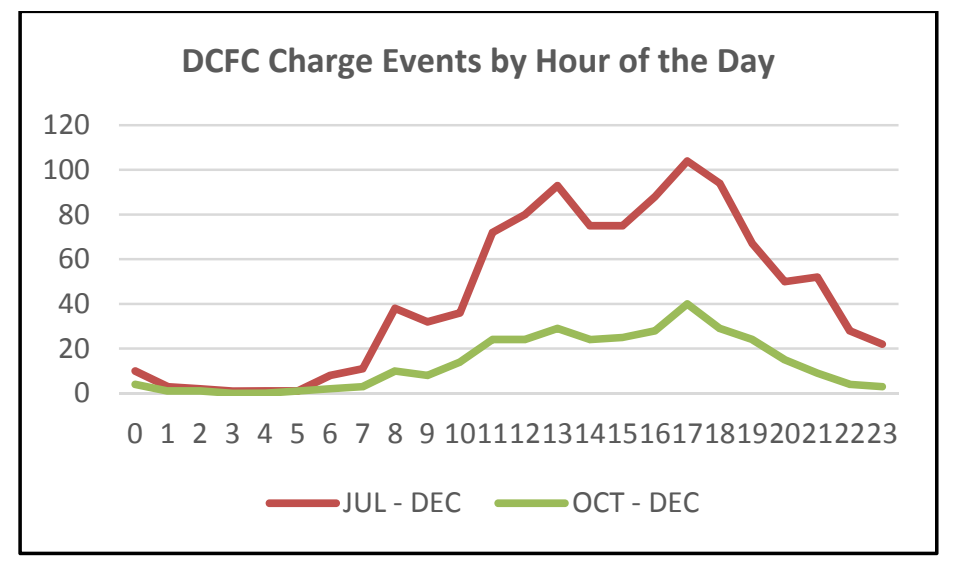

Figure 5. Hour of the day when popular DCFCs were used over the last 6 months and last 3 months of 2013.

Figures 4 and 5 also show an increase in utilization around the lunch hour (11 a.m. to 2 p.m.).

\section{Where were the Frequently Used Direct Current Fast Chargers Used?}

The most used DCFCs were used by Leaf drivers who were an average of 17.1 miles away from their home base. Because the average distance Leaf drivers were away from home is not particularly informative about where Leaf drivers chose to fast charge, Figure 6 provides a breakdown of the distance from home that 
charging took place, showing that $86 \%$ of all fast charging throughout The EV Project took place within 30 miles of the EV driver's home base. Less than $4 \%$ of all fast charging throughout The EV Project took place at more than $\mathbf{5 0}$ miles (which is approximately one-half of the range of the Nissan leaf) from home, indicating that a few drivers were willing to take a long trip, anticipating that they will fast charge to return home.

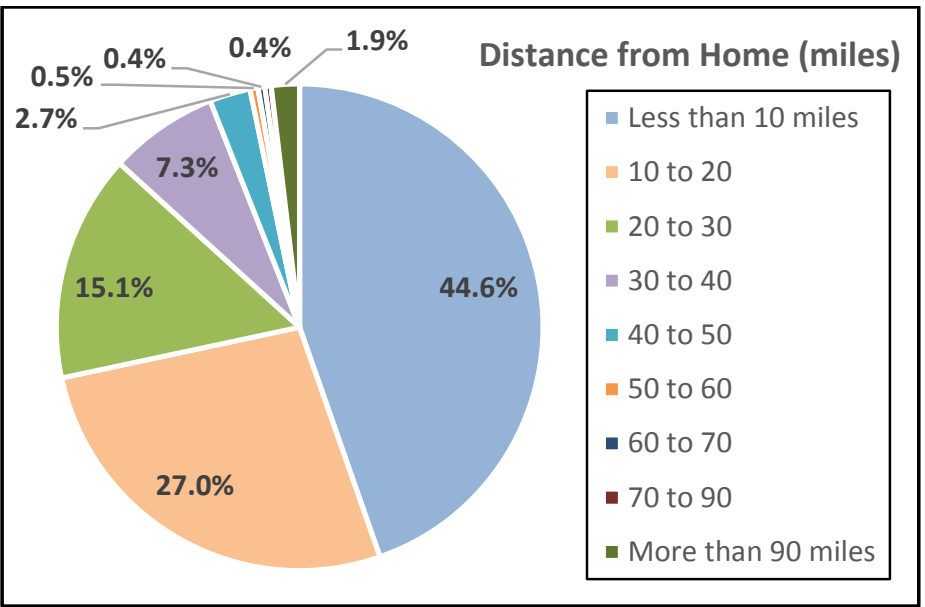

Figure 6. Distance from home (miles) where PEV drivers used the most popular DCFCs (over full term).

This result is somewhat surprising, because it is commonly believed that fast charging is done when the EV driver "needs" a charge opposed to using slower charging at AC Level 2 or Level 1, which is more typically assumed to be a "convenience" charge. The need for a charge could take place on the way home; however, the very high percentage of Leaf drivers charging very close to home (i.e., within 10 miles) makes this a questionable conclusion to draw.

This result can be explained somewhat by the fact that for most of The EV Project, DCFC use was free. An examination of the last 6 months of 2013, when most of the Blink DCFC had implemented access fees, shows an expected increase in the average distance from home the charging occurred (20.7 miles). However, a significant percentage (i.e., $37.9 \%$ of DCFC) still occurred within 10 miles of home and, as shown in Figure 7, charging within 30 miles of home still represents $86 \%$ of all DCFC events.

As stated earlier, the commonly held assumption is that fast charging is done out of necessity, whilst away from home and alternating current (AC) Level 2 charging is done when a charging station is available at or near where the electric vehicle driver parks. In other words, DCFC are oftentimes a destination, while AC Level 2 charging is done when convenient to a destination.

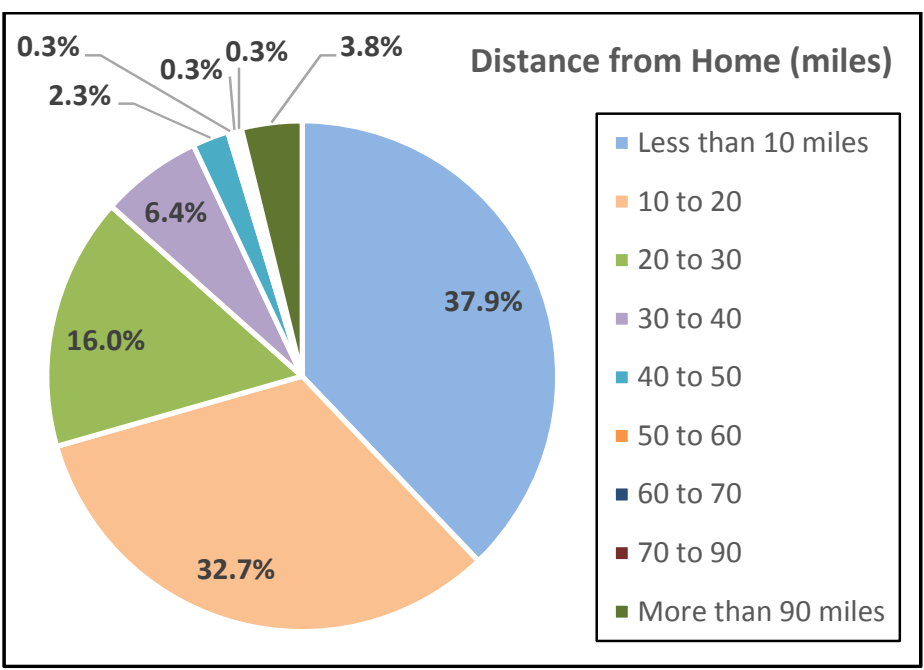

Figure 7. Distance from home (miles) where PEV drivers used the most popular DCFCs (over last 6 month of 2013).

\section{What was the Battery's State-Of-Charge When the Frequently Used Direct Current Fast Chargers were Used?}

Figure 8 shows the battery SOC at the beginning of a fast charge event for all of The EV Project. The $y$-axis in Figure 8 is the percentage of all fast charging represented by the range of SOC\% at the start of the charge.

Figure 8 shows that SOC at the start of fast charging is significantly lower at the start of charging for all other away-from-home charging (Level 2 AC).

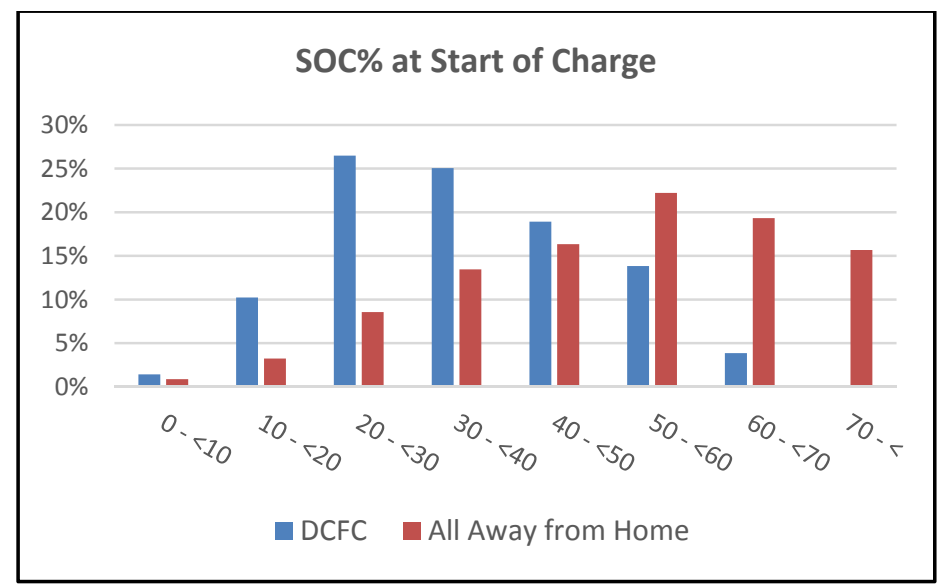

Figure 8. Percentage of away from home charging (y-axis) that takes place at SOC range (x-axis).

The average SOC when Leaf drivers in The EV Project elected to fast charge was $35.4 \%$. Further examination of SOC\% at the start of fast charging can be seen in Figure 9. The scatter graph shows a greater density of soc\% just below $30 \%$, but overall it appears to be a 
fairly broad distribution. The same data are seen in Figure 10, with the histogram showing that the most frequent SOC\% at the start of fast charge between $25 \%$ and $30 \%$.

This SOC data are for The EV Project in its entirety. As we have seen with the distance from home analysis above, there was some modification in charging behavior when access fees were introduced.

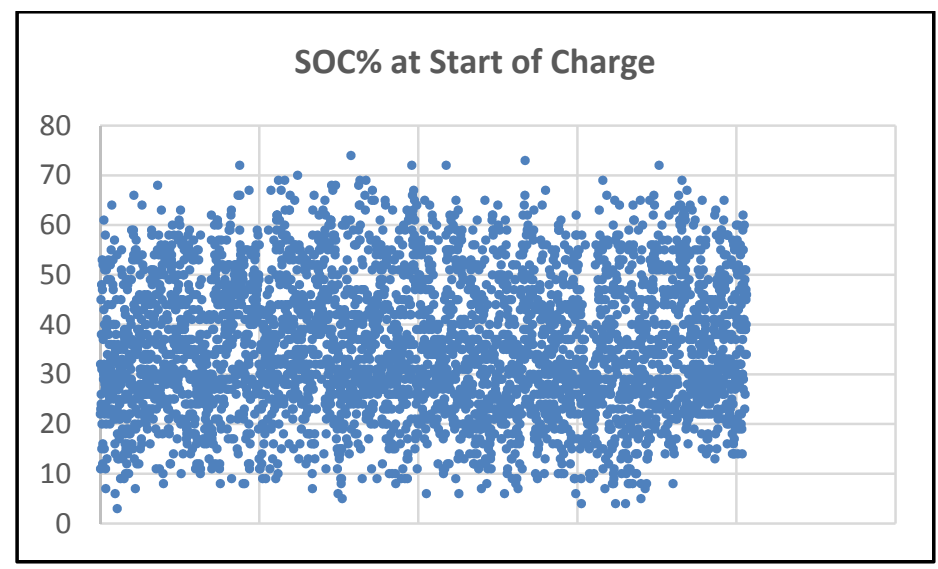

Figure 9. Scatter plot of SOC as percentage of full (100\%) at the start of each DCFC event.

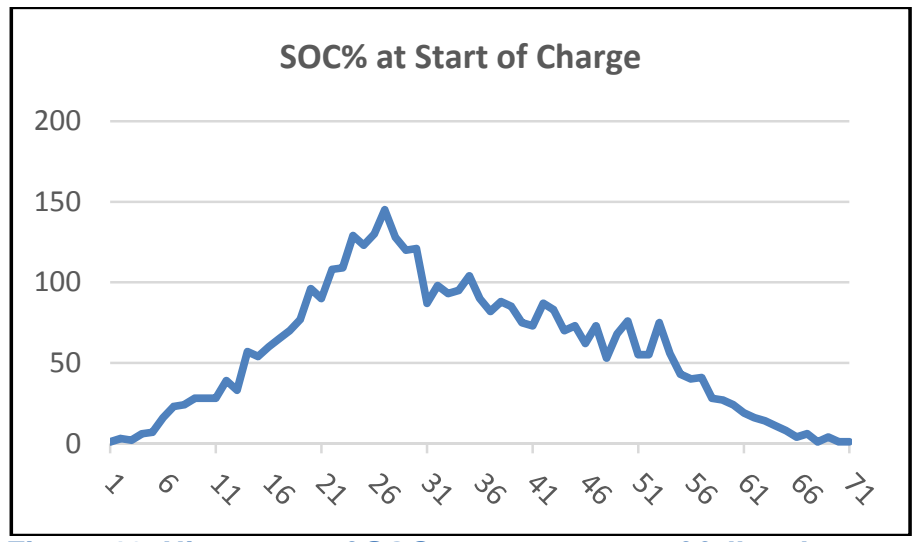

Figure 10. Histogram of SOC as percentage of full at the start of DCFC (x-axis) and number of charge events at that starting SOC percentage (y-axis)

The scatter plot for the last 6 months of 2013 shown in Figure 11 appears more evenly distributed with some increased density between 15 and $45 \%$.

However, the histogram in Figure 12, which is also for the last 6 months of 2013,shows a similar peak in the frequency of use as was seen for the project overall between 25 and $30 \%$.

One of the unexpected results of this analysis, which was discussed above, was the fact that a significant percentage of DCFC events took place less than 10 miles from the Leaf's home base. Further analysis of the SOC\% condition at the start of these charge events showed that the average SOC\% at the start was only about $1 \% t$ lower than the overall average SOC\% for each of the periods examined (Table 1).

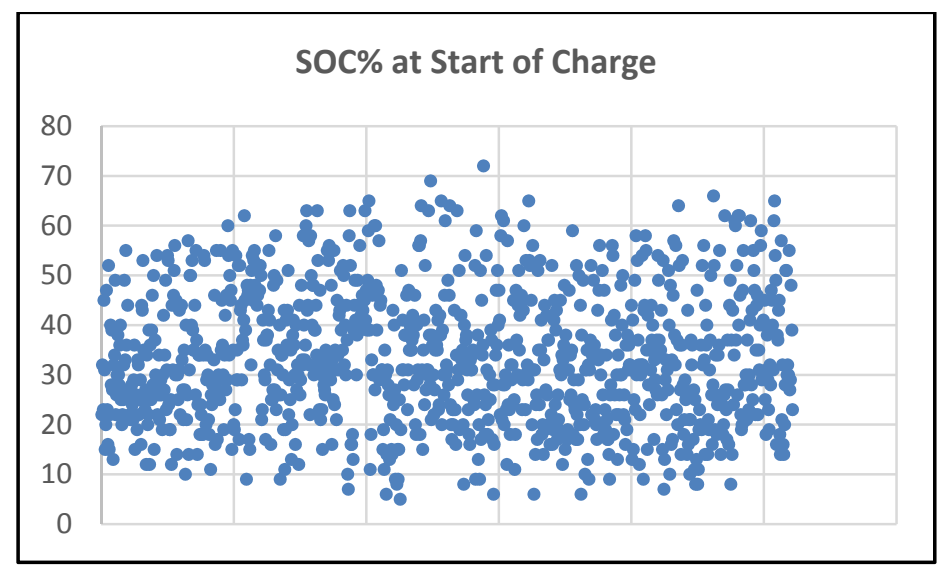

Figure 11. Scatter plot of SOC as percentage of full (100\%) at the start of each DCFC event (July through December 2013).

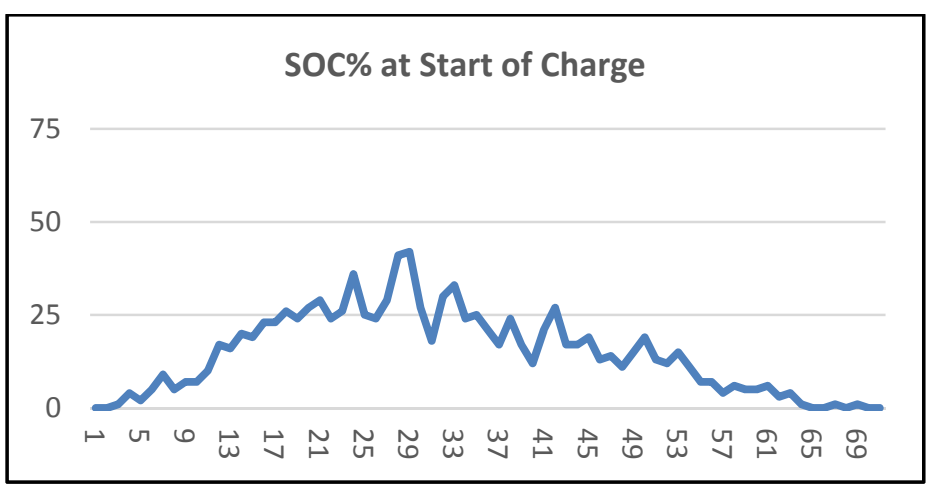

Figure 12. Histogram of SOC as percentage of full at the start of DCFC (x-axis) and number of charge events at that starting SOC percentage (y-axis) (July through December 2013).

Table 1. Average SOC\% at the start of the DCFC event.

\begin{tabular}{|l|c|c|}
\hline \multicolumn{1}{|c|}{ Average SOC\% } & Full EV Project & Jul-Dec $\mathbf{2 0 0 3}$ \\
\hline All & $35.40 \%$ & $33.10 \%$ \\
\hline Less than 10 miles from home & $34.35 \%$ & $31.90 \%$ \\
\hline
\end{tabular}

A histogram showing the SOC\% at the start of charge for those fast charge events taking place within 10 miles of the electric vehicle's home base is shown in Figure 13. The peak of this graph is between 22 and 29. This represents a peak that is only slightly to the left (lower) than it was in Figure 10.

This consistent SOC\% at the start of charge even for those near home indicates that fast-charging was not often used for trips going far from home, but for additional trips in the area near their home. 


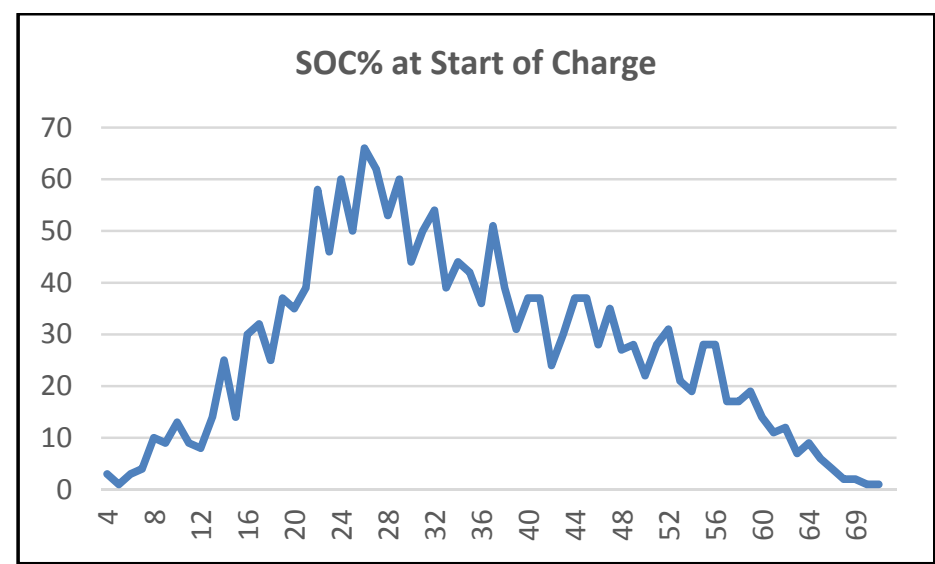

Figure 13. Histogram of SOC as a percentage of full at the start of DCFC (x-axis), and number of charge events at that starting SOC percentage (y-axis) taking place within 10 miles of home base.

\section{Conclusions}

Utilization of the most popular DCFCs deployed in The EV Project by Leaf drivers showed that they charged when needed regardless of the day of the week and at a consistently lower initial SOC\% than at non-residential AC Level 2 stations.

Fast charging occurred primarily at the DCFC stations near the end of the work day when drivers were either headed home or as, the SOC\% indicates, had other evening plans for which they wanted to ensure sufficient available range.

Because the Leaf drivers were typically not far from home when they used the DCFCs and they were not charging at lower SOC when they were near home, the use of Blink DCFC stations appears to be done in order to regain the flexibility that comes from a full charge, rather than providing enough range to return home.

\section{About The EV Project}

The EV Project was the largest PEV infrastructure demonstration project in the world, equally funded by the United States Department of Energy (DOE) through the American Recovery and Reinvestment Act and private sector partners. The EV Project deployed over 12,000 AC Level 2 charging stations for residential and commercial use and over 100 dual-port DCFC in 17 U.S. regions. Approximately 8,300 Nissan LEAFs ${ }^{\mathrm{TM}}$, Chevrolet Volts, and Smart ForTwo Electric Drive vehicles were enrolled in the project.

Project participants gave written consent for EV Project researchers to collect and analyze data from their vehicles and/or charging units. Data collected from the vehicles and charging infrastructure represented almost 125 million miles of driving and 4 million charging events. The data collection phase of The EV Project ran from January 1, 2011, through December 31, 2013. INL is responsible for analyzing the data and publishing summary reports, technical papers, and lessons learned on vehicle and charging unit use.

\section{Company Profile}

INL is one of DOE's 10 multi-program national laboratories. The laboratory performs work in each of DOE's strategic goal areas: energy, national security, science, and the environment. INL is the nation's leading center for nuclear energy research and development. Day-to-day management and operation of the laboratory is the responsibility of Battelle Energy Alliance.

For more information, visit avt.inl.gov/evproject.shtml and avt.inl.gov/chargepoint.shtml.

\section{References}

1. CHAdeMO Association http://www.chademo.com/wp/ 